Eur. J. Clin. Chem. Clin. Biochem.

Vol. 31, 1993, pp. 407-411

(C) 1993 Walter de Gruyter \& Co. Berlin - New York

\title{
Increase of Serum $\alpha_{1}$-Acid Glycoprotein Despite the Decline of Liver Synthetic Function in Cirrhotics with Hepatocellular Carcinoma
}

\author{
By E. Falleti ${ }^{1}$, M. Pirisi ${ }^{2}$, C. Fabris ${ }^{2}$, Nadia Bortolotti ${ }^{1}$, G. Soardo ${ }^{2}$, P. Toniutto ${ }^{2}$, F. Gonano ${ }^{1}$ and E. Bartoli ${ }^{2}$ \\ 1 Cattedra di Patologia Clinica, \\ 2 Cattedra di Medicina Interna, \\ Università degli Studi, Udine, Italia
}

(Received January 1/April 15, 1993)

Summary: $\alpha_{1}$-Acid glycoprotein, an acute phase reactant synthesised by the liver, has been reported to be increased in neoplastic conditions and reduced in chronic liver disease. We measured serum $\alpha_{1}$-acid glycoprotein by a nephelometric method in 186 subjects (112 males, 74 females): 55 had mild chronic liver disease (chronic hepatitis and steatofibrosis), 45 cirrhosis, 38 hepatocellular carcinoma, 15 extra-hepatic malignant disease; 33 healthy subjects were used as controls. Analysis of variance demonstrated a significant variability among groups $(F=17.08, P=0.0000)$. Higher concentrations of $\alpha_{1}$-acid glycoprotein were detected in malignant extra-hepatic disease than in all other groups $(P<0.01)$; concentrations of $\alpha_{1}$-acid glycoprotein were higher in hepatocellular carcinoma than in cirrhosis $(\mathrm{P}<0.01)$. Multiple regression analysis by groups (dependent variable $=\alpha_{1}$-acid glycoprotein; group $1=$ mild chronic liver disease + cirrhosis; group $2=$ hepatocellular carcinoma) showed a significant correlation for both group $1(\mathrm{r}=0.6264, \mathrm{~F}=8.005, \mathrm{P}=0.0000)$ and group 2 $(\mathrm{r}=0.8947, \mathrm{~F}=13.643, \mathrm{P}=0.0000)$. The significant standardised regression coefficients were: cholinesterase, $\mathrm{C}$-reactive protein, $\gamma$-glutamyltransferase and iron (negative) for regression upon group 1; C-reactive protein, $\alpha_{1}$-antiproteinase, $\gamma$-glutamyltransferase, iron (negative) for regression upon group 2. A difference between the 2 regression equation coefficients was detected $(F=5.209, P=0.0002)$. In conclusion, a raised $\alpha_{1}$-acid glycoprotein concentration was found in patients with malignancies, both hepatic and extra-hepatic; however, patients with hepatocellular carcinoma had a lower $\alpha_{1}$-acid glycoprotein concentration than patients with malignant extra-hepatic disease. In hepatocellular carcinoma, a good correlation existed between $\alpha_{1}$-acid glycoprotein and other serum indices of the acute phase response. In some patients with hepatocellular carcinoma, $\alpha_{1}$-acid glycoprotein was increased, despite the decrease of liver function.

\section{Introduction}

$\alpha_{1}$-Acid glycoprotein is a circulating glycoprotein synthesized mainly in the liver. It has a relative molecular mass of about 41000 and is characterized by the presence of five glycosylation sites $(1,2) . \alpha_{1}$-Acid glycoprotein has long been recognized as an acute phase reactant (3). Thus, its concentration increases $2-10$ fold in serum, under conditions that promote the increase of other acute phase proteins such as $\alpha_{1}$ antiproteinase and $\mathrm{C}$-reactive protein; moreover, its synthesis in human adult hepatocytes is augmented by interleukin-1 and interleukin-6, cytokines that are considered the main mediators of the acute phase response (4).

Previous studies have shown that the $\alpha_{1}$-acid glycoprotein concentration rises in serum during the course of several neoplastic diseases (5-7), including hepatocellular carcinoma in Asian patients (8).

However, hepatocellular carcinoma has a striking geographical variation and in industrialised countries, where its incidence is relatively low, hepatocellular 
carcinoma develops almost always in patients with long-standing cirrhosis. In contrast, in high incidence areas (e.g. Far-East Asia) hepatocellular carcinoma is common even in the absence of cirrhosis (9). Unlike other acute phase reactants (like $\alpha_{1}$-antiproteinase), $\alpha_{1}$-acid glycoprotein does not increase in advanced chronic liver disease and may be actually markedly decreased in such conditions $(10-13)$. In this context, the question arises as to whether the variations of $\alpha_{1}$ acid glycoprotein concentration in the acute phase response to neoplasia is influenced by the decline of the hepatic synthetic function, which accompanies the development of hepatocellular carcinoma in a cirrhotic liver. The aim of the present study was to ascertain the existence or otherwise of such a pathophysiological interaction.

\section{Materials and Methods}

\section{Patients}

We studied a total of 186 subjects (112 male and 74 female, mean age $54.5 \pm 14.2$ years), divided in 5 categories according to their diagnosis; their characteristics are listed in table 1 . The following criteria used for the definition of the categories.

Mild chronic liver disease was defined, on the histological evidence of percutaneous liver biopsy, as a) chronic persistent hepatitis, b) chronic active hepatitis, or c) steatofibrosis.

Cirrhosis was diagnosed on the basis of clinical evidence (hypoalbuminaemia, hypergammaglobulinaemia, ascites, oesophageal varices) and/or histological evidence of cirrhosis; development of primary liver cancer in patients belonging to this group was excluded on the basis of negative results of diagnostic imaging and biohumoral ( $\alpha_{1}$-fetoprotein) tests.

Conversely, hepatocellular carcinoma, which in our patients always developed in the setting of long-standing liver cirrhosis, was always confirmed histologically or at autopsy.

Malignant disease of extra-hepatic origin was also diagnosed histologically or at autopsy; more precisely, this group contained 5 patients with pancreatic carcinoma, 5 with gastric carcinoma, 1 with oesophageal carcinoma, 1 with ovarian cancer, 1 with lung cancer, 1 with high-grade non-Hodgkin lymphoma, 1 with malignant pheochromocytoma. Eight of these patients had evidence of hepatic metastases at the time serum was collected for the present study.

Healthy blood donors were used as a control group.

\section{Biochemical determinations}

Sera were immediately stored at $-20^{\circ} \mathrm{C}$ after collection and kept frozen until use. At the time the determination of $\alpha_{1}$-acid glycoprotein was performed, sera ha, been stored for a maximum of 12 months. $\alpha_{1}$-Acid glycoprotein was determined simultaneously in all sera with a nephelometric method (BNA, Behring, Germany). Intra-assay and inter-assay coefficients of variations were $2.0 \%$ and $3.5 \%$, respectively.

All other determinations were performed with standard commercial kits.

\section{Statistical analysis}

One-way analysis of variance was applied to detect differences in the population means with regard to $\alpha_{1}$-acid glycoprotein concentrations. Bonferroni's test was used for multiple comparisons among the groups. One-way analysis of covariance was used to exclude the possibility that variations of renal function (measured by serum creatinine) might exert a decisive influence on $\alpha_{1}$-acid glycoprotein concentration. The Pearson $\chi^{2}$-test was used to test the existence of differences among the groups with regard to categorized variables (such as normal or pathological $\alpha_{1}$-acid glycoprotein concentration). Multiple regression analysis was utilized to investigate the correlation of serum $\alpha_{1}$-acid glycoprotein variations with variations of several other biohumoral conditions. The analysis was performed on the patients as a single group, as well as on 2 subgroups (first subgroup: chronic liver disease + cirrhosis; second subgroup: hepatocellular carcinoma). In order to detect differences in the slopes or the intercepts between the regressions of the subroups, analysis of variance of the regression coefficients was performed. In view of their scattered distribution, the results of $\alpha_{1}$-acid glycoprotein and C-reactive protein determinations were transformed logarithmically when appropriate. All statistical tests were performed with the BMDP ${ }^{\mathrm{TM}}$ statistical software package (14).

\section{Results}

Figure 1 presents the individual values of serum $\alpha_{1}$ acid glycoprotein measured in the various groups of patients. Using a cut-off value of $1 \mathrm{~g} / \mathrm{l}$, we detected a significant difference between the observed and the expected frequency of pathological $\alpha_{1}$-acid glycoprotein values (Pearson $\chi^{2}$-test $65.93, \mathrm{P}=0.0000$ ). $\alpha_{1}$ Acid glycoprotein was higher in patients with malignancies (both hepatic and extra-hepatic). One-way analysis of variance demonstrated the existence of a significant difference among groups $(F=17.08$, $\mathrm{P}=0.0000$ ). Patients with malignant extra-hepatic

Tab. 1. Characteristics of the studied population.

\begin{tabular}{|c|c|c|c|c|c|}
\hline & \multirow[t]{2}{*}{$\mathbf{N}$} & \multicolumn{2}{|c|}{ Sex } & \multirow{2}{*}{$\begin{array}{l}\text { Age } \\
(a, \bar{x} \pm S D)\end{array}$} & \multirow{2}{*}{$\begin{array}{l}\text { Age range } \\
\text { (a) }\end{array}$} \\
\hline & & $\sigma$ & q & & \\
\hline $\begin{array}{l}\text { Healthy controls } \\
\text { Chronic liver disease } \\
\text { Liver cirrhosis } \\
\text { Hepatocellular carcinoma } \\
\text { Extra-hepatic malignancies }\end{array}$ & $\begin{array}{l}33 \\
55 \\
45 \\
38 \\
15\end{array}$ & $\begin{array}{l}15 \\
31 \\
22 \\
34 \\
10\end{array}$ & $\begin{array}{l}18 \\
24 \\
23 \\
04 \\
05\end{array}$ & $\begin{array}{l}41.8 \pm 14.7 \\
51.0 \pm 13.1 \\
58.3 \pm 11.0 \\
62.6 \pm 11.6 \\
62.8 \pm 08.1\end{array}$ & $\begin{array}{l}20-68 \\
21-73 \\
36-76 \\
33-80 \\
43-77\end{array}$ \\
\hline
\end{tabular}




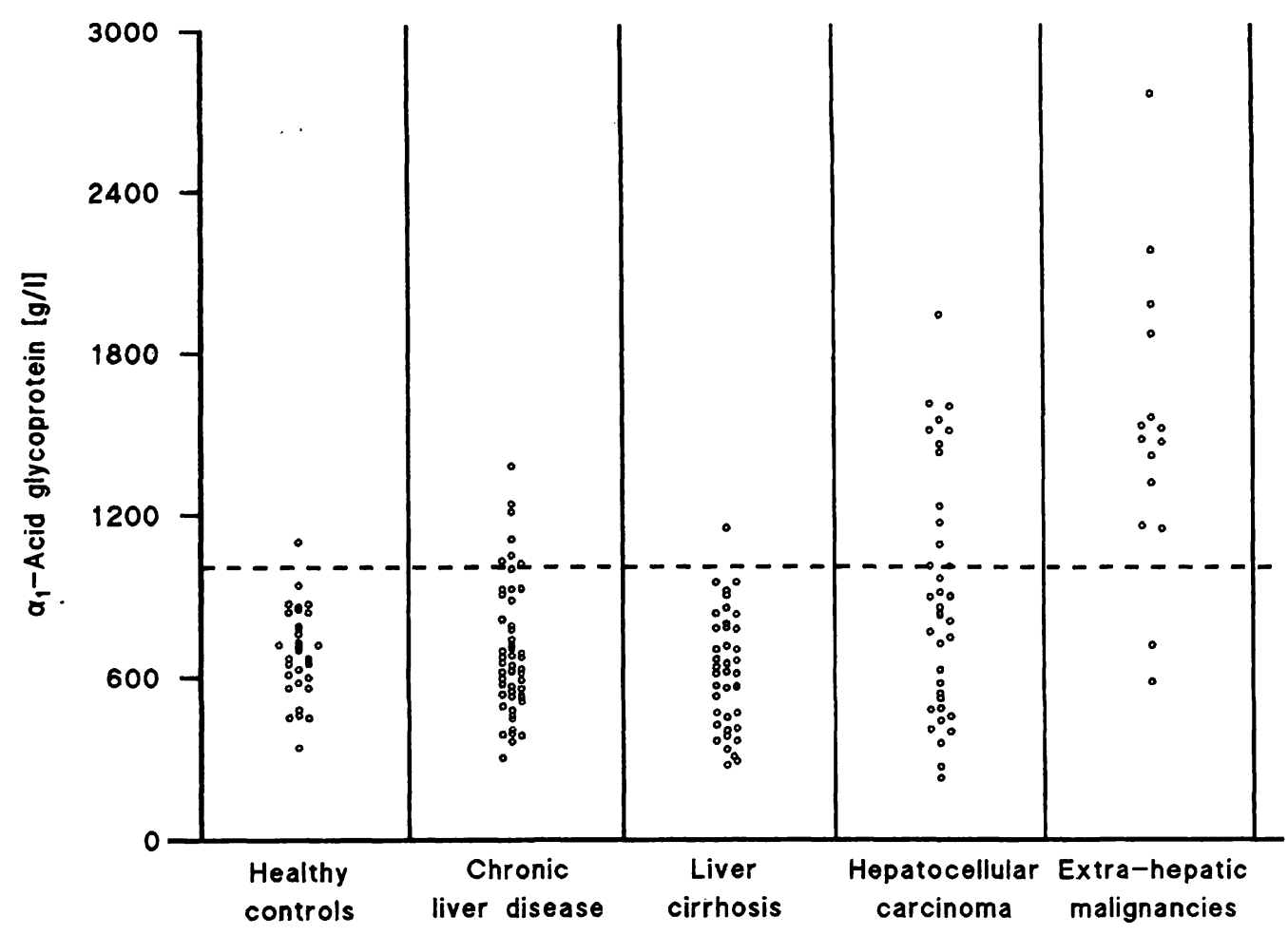

Fig. 1. Individual values of $\alpha_{1}$-acid glycoprotein grouped according to diagnosis. The dotted line represents the upper reference limit $(1 \mathrm{~g} / \mathrm{l})$.

Tab. 2. Multiple regression analysis. The analysis was performed using $\alpha_{1}$-acid glycoprotein as the dependent variable and cholinesterase, $C$-reactive protein, $\alpha_{1}$-antiproteinase, $\gamma$-glutamyltransferase and iron as predictor variables. The regression analysis was performed on the total collective, as well as on separate groups.

\begin{tabular}{lllrr}
\hline Regression & Multiple $r$ & Multiple $\mathrm{r}^{2}$ & $\mathrm{~F}$ & $\mathrm{P}$ \\
\hline All patients & 0.6140 & 0.3770 & 10.287 & 0.0000 \\
Chronic non-neoplastic liver disease & 0.6264 & 0.3923 & 8.005 & 0.0000 \\
Hepatocellular carcinoma & 0.8947 & 0.8005 & 13.643 & 0.0000 \\
\hline
\end{tabular}

disease had higher $\alpha_{1}$-acid glycoprotein concentrations than all other groups $(P<0.01)$; patients with hepatocellular carcinoma had higher concentrations than cirrhotics $(P<0.01)$ (Bonferroni's test for pairwise comparisons). Table 2 shows the results of the multiple regression analysis, taking serum $\alpha_{1}$-acid glycoprotein as the dependent variable, and C-reactive protein, $\quad \alpha_{1}$-antiproteinase, cholinesterase, $\left.{ }^{1}\right) \quad \gamma$ glutamyltransferase ${ }^{1}$ ) and iron serum concentrations as predictor variables. The analysis was performed for the subjects as a single collective, as well as by groups. In the analysis of the single collective, the standardized regression coefficients of all predictor variables were found to be significant: $\alpha_{1}$-antiproteinase $(T=3.48, \quad P=0.00), \quad C$-reactive protein $(T=3.60, \quad P=0.00)$, cholinesterase $(T=4.20$, $\mathrm{P}=0.00), \quad \gamma$-glutamyltransferase $\quad(T=2.07$,

1) Cholinesterase (EC 3.1.1.8)

$\gamma$-Glutamyl transpeptidase (EC 2.3.2.2)

Sialyltransferase (EC 2.4.99.6)
$P=0.04)$ and iron $(T=-2.93, P=0.00)$. In the analysis of results from patients with chronic, nonneoplastic liver disease, significant standardized regression coefficients were found for iron $(T=-3.12$, $\mathrm{P}=0.00)$, C-reactive protein $(\mathrm{T}=2.51, \mathrm{P}=0.01)$, $\gamma$-glutamyltransferase $(T=2.22, P=0.03)$ and cholinesterase $(T=3.26, P=0.00)$. In the analysis of results from patients with hepatocellular carcinoma, significant standardized regression coefficients were found for $\alpha_{1}$-antiproteinase ( $\mathrm{T}=7.54, \mathrm{P}=0.00$ ), $\mathrm{C}$ reactive protein $(\mathrm{T}=4.01, \mathrm{P}=0.00), \gamma$-glutamyltransferase $(T=2.12, \quad P=0.05)$ and iron $(\mathrm{T}=-2.75, \mathrm{P}=0.01)$. The analysis of variance of regression coefficients over groups was also statistically significant $(F=5.209, P=0.0002)$. Finally, serum creatinine displayed a significant correlation with $\alpha_{1}$-acid glycoprotein $(r=0.170, P=0.024)$. However, analysis of covariance enabled us to prove that a significant variability among groups with regard to $\alpha_{1}$-acid glycoprotein concentration still existed after adjustment for creatinine $(F=13.16, P=0.000)$. 


\section{Discussion}

In the present study, the great majority of our.patients with extra-hepatic malignant disease $(86.7 \%$ of this group) had an $\alpha_{1}$-acid glycoprotein concentration above a cut-off value of $1 \mathrm{~g} / \mathrm{l}$ (representing mean \pm 2 SD of our control subjects). Moreover, this group of patients exhibited the highest $\alpha_{1}$-acid glycoprotein values. In contrast, only $34.2 \%$ of patients with hepatocellular carcinoma showed $\alpha_{1}$-acid glycoprotein concentrations above the cut-off. Although $\alpha_{1}$-acid glycoprotein was significantly increased in hepatocellular carcinoma in comparison to cirrhosis, it was also significantly lower in comparison with other neoplastic diseases. Patients with chronic, non-malignant liver disease did not differ from controls with respect to $\alpha_{1}$-acid glycoprotein.

Serum concentrations of glycoproteins can be influenced by the mass of functional liver in various ways. Firstly, an impairment of hepatic synthetic ability might lead to a decrease of their production, since they are mostly synthesized by the liver. In effect, our data indicate that the $\alpha_{1}$-acid glycoprotein concentrations of patients with chronic, non-neoplastic disease of the liver show a positive correlation with cholinesterase, one of the more reliable indices of liver synthetic function. However, the liver is also the main site of glycoprotein catabolism, which depends on uptake through specific surface receptors which recognize asialoforms of circulating glycoproteins (15). $\alpha_{1}$-Acid glycoprotein appears to have a higher clearance rate than other glycoproteins expressed during the acute phase response, like ceruloplasmin and haptoglobin (16). Therefore, serum $\alpha_{1}$-acid glycoprotein concentration might increase because less is taken up by the reduced hepatic mass (17). We found similar $\alpha_{1}$-acid glycoprotein concentrations among patients with chronic non-neoplastic liver disease and control subjects. A possible explanation of this finding might be the existence in the organism of a balance that is maintained between reduced synthesis and impaired catabolism of this glycoprotein. However, in the pres-

\section{References}

1. Arnaud, P., Miribel, L. \& Roux, A. F. (1988) Alpha 1-acid glycoprotein. Methods Enzymol. 163, 418-430.

2. Schmid, K. (1989) Human plasma alpha 1-acid glycoprotein - biochemical properties, the amino acid sequence and the structure of the carbohydrate moiety, variants and polymorphism. Prog. Clin. Biol. Res. 300, 7-22. ence of an acute phase response, as in neoplastic conditions, a raised proportion of glycoprotein sialoforms (not recognized by liver cell receptors which are able to recognize only asialoforms, as noted above) appears in the serum $(18,19)$. Thus, one might speculate that the equilibrium that seems to exist in chronic, non-neoplastic liver disease could be disrupted by the appearance of an increased proportion of sialo-forms of $\alpha_{1}$-acid glycoprotein, possibly related to increased sialyltransferase $\left.{ }^{1}\right)$ activity $(13,19-23)$. In accordance with this hypothesis, $\alpha_{1}$-acid glycoprotein showed a strong correlation with other acute phase indices $\left(\alpha_{1}\right.$-antiproteinase, C-reactive protein and iron) in the group of patients with hepatocellular carcinoma.

Our data are only in partial agreement with previous reports (8). The incidence of pathologically elevated $\alpha_{1}$-acid glycoprotein concentrations was not as high as that previously described in hepatocellular carcinoma in Asian patients. Geographical variations in the clinical presentation of hepatocellular carcinoma might explain this discrepancy, since our patients were all Italian and developed primary liver cancer always in the setting of long-standing cirrhosis. A correct interpretation of these results in relation to earlier conflicting studies is limited by the fact that we could not test sera of patients with hepatocellular carcinoma of different geographical origin. The existence of these differences may, however, represent indirect confirmation of the hypothesis that the decline of liver synthetic function limits the rise of $\alpha_{1}$-acid glycoprotein serum concentration in patients with the type of hepatocellular carcinoma commonly encountered in our country.

In conclusion, $\alpha_{1}$-acid glycoprotein was found to be elevated in hepatocellular carcinoma, but it was not as high as in patients with extra-hepatic tumours. A good correlation existed between $\alpha_{1}$-acid glycoprotein and other serum indices of the acute phase response; in this setting, it appears that $\alpha_{1}$-acid glycoprotein is able to increase despite a decline of liver function.
3. Thompson, D., Milford-Ward, A. \& Whicher, J. T. (1992) The value of acute phase protein measurements in clinical practice. Ann. Clin. Biochem. 29, 123-131.

4. Heinrich, P. C., Castell, J. V. \& Andus, T. (1990) Interleukin- 6 and the acute phase response. Biochem. J. 265, 621 636. 
5. Hansen, J. E., Iversen, J., Lihme, A. \& Bog-Hansen, T. C. (1987) Acute phase reaction, heterogeneity, and microheterogeneity of serum proteins as nonspecific tumor markers in lung cancer. Cancer 60,1630-1635.

6. Avall Lundqvist, E., Blad, E., Xiao, L., Sjovall, K. \& Eneroth, P. (1991) Pretreatment serum levels of C-reactive protein, $\alpha_{1}$-antitrypsin, haptoglobin, $\alpha_{1}$-acid glycoprotein and tissue polypeptide antigen in cervical carcinoma. Eur. J. Gynaecol. 12, 375-383.

7. Robertson, J. F., Pearson, D., Price, M. R., Selby, C., Pearson, J., Blamey, R. W. \& Howell, A. (1991) Prospective assessment of the role of five tumour markers in breast cancer. Cancer Immunol. Immunother. 33, 403-410.

8. Chio, L. F. \& Oon, C. J. (1979) Changes in serum alpha antitrypsin, alpha ${ }_{1}$ acid glycoprotein and $\beta_{2}$-glycoprotein I in patients with malignant hepatocellular carcinoma. Cancer 43, 596-604.

9. Kew, M. C. (1990) Tumors of the liver. In: Hepatology A Textbook of Liver Disease, 2nd edn. (Zakim, D. \& Boyer, T. D., eds.) pp. 1206-1240, W. B. Saunders Company, Philadelphia.

10. Hallen, J. \& Laurell, C. B. (1972) Plasma protein pattern in cirrhosis of the liver. Scand. J. Clin. Lab. Invest. 20 (Suppl. 124), 97-103.

11. Kindmark, C. O. \& Laurell, C. B. (1972) Sequential changes of the plasma protein pattern in inoculation hepatitis. Scand. J. Clin. Lab. Invest. 20 (Suppl. 124), 105-115.

12. Joelsson, B., Alwmark, A., Gullstrand, P., Bengmark, S. \& Hultberg, B. (1987) Serum proteins in liver cirrhosis: effects of shunt surgery. J. Clin. Chem. Clin. Biochem. 25, 865868.

13. Biou, D., Chanton, P., Konan, D., Seta, N., N'Guyen, H., Feger, J. \& Durand, G. (1989) Microheterogeneity of the carbohydrate moiety of human $\alpha_{1}$-acid glycoprotein in two benign liver diseases: Alcoholic cirrhosis and acute hepatitis. Clin. Chim. Acta 186, 59-66.

14. Dixon, W. J., Brown, M. B., Engelman, L. \& Jennrich, R. I. (1990) BMDP statistical software manual, University of California Press, Berkeley.
15. Ashwell, G. \& Morell, A. G. (1974) The role of surface carbohydrates in the hepatic recognition and transport of circulating glycoproteins. In: Advances in Enzymology (Meister, A., ed.) vol. 41, pp. 99-128, John Wiley and Sons, New York.

16. Morell, A. G., Gregoriadis, G., Scheinberg, I. H., Sternleib, I. \& Ashwell, G. (1971) The role of sialic acid in determining the survival of glycoproteins in the circulation. J. Biol. Chem. 246, $1461-1467$.

17. Sawamura, T., Nakada, H., Hazama, H., Shiozaki, Y., Sameshima, Y. \& Tashiro, Y. (1984) Hyperasialoglycoproteinemia in patients with chronic liver diseases and/or liver cell carcinoma. Gastroenterology 87, 1217-1221.

18. Moule, S. K., Peak, M., Thompson, S. \& Turner, G. A. (1987) Studies of the sialylation and microheterogeneity of human serum $\alpha_{1}$-acid glycoprotein in health and disease. Clin. Chim. Acta 166, 177-185.

19. Turner, G. A. (1992) N-glycosylation of serum proteins in disease and its investigation using lectins. Clin. Chim. Acta $208,149-171$

20. Serbource-Goguel, N., Corbic, M., Erlinger, S., Durand, G., Agneray, J. \& Feger, J. (1983) Measurement of serum $\alpha_{1}$-acid glycoprolein and $\alpha_{1}$-antitrypsin desialylation in liver disease. Hepatology 3, 356-359.

21. Sebource-Goguel, N., Durand, G., Corbic, M., Agneray, B. \& Feger, J. (1986) Alterations in relative proportions of microheterogeneous forms of human $\alpha_{1}$-acid glycoprotein in liver disease. J. Hepatol. 2, 245-252.

22. Jezequel, M., Seta, N. S., Corbic, M. M., Feger, J. M. \& Durand, G. M. (1988) Modifications of concanavalin A patterns of $\alpha_{1}$-acid glycoprotein and $\alpha_{2}$-HS glycoprotein in alcoholic liver disease. Clin. Chim. Acta 176, 49-57.

23. Sobue, G. \& Kosaka, A. (1980) Asialoglycoproteinemia in a case of primary hepatic cancer. Hepato-Gastroenterol. $27,200-203$.

Dr. Mario Pirisi
Cattedra di Medicina Interna
Università degli Studi
Piazzale Santa Maria della Misericordia 1
I-33100 Udine
Italy


